\title{
Prevalence of refractive error and visual impairment among school-age children of Hargesia, Somaliland, Somalia
}

Zahra Abdi Ahmed, ${ }^{1}$ Saif Hassan Alrasheed ${ }^{2,3}$ and Waleed Alghamdi ${ }^{3}$

${ }^{1}$ Department of Primary Eye Care, Faculty of Optometry and Visual Sciences, Al-Neelain University, Khartoum, Sudan. ${ }^{2}$ Department of Binocular Vision, Faculty of Optometry and Visual Sciences, Al-Neelain University, Khartoum, Sudan (Correspondence to: Saif Alrasheed: s.rasheed@qu.edu.sa). 3Department of Optometry, College of Applied Medical Sciences, Qassim University, Qassim, Saudi Arabia.

\begin{abstract}
Background: Childhood visual impairment is a global public health problem, especially in low and middle-income countries. Its most common causes are avoidable by early diagnosis and treatment.

Aims: To assess prevalence of refractive error and visual impairment among school-aged children in Hargeisa, Somaliland, Somalia.

Methods: This was a cross-sectional study of 1204 students (aged 6-15 years) in 8 randomly selected primary schools in Hargeisa from November 2017 to January 2018. We used the modified Refractive Error Study in Children to determine prevalence of refractive error and visual impairment, including the following investigations: distance visual acuity, assessed by Snellen Tumbling E-chart; refraction, assessed by retinoscope binocular vision assessment; and examination of anterior and posterior segments.

Results: Prevalence of uncorrected, presenting and best-corrected visual impairment of $6 / 12$ or worse was $13.6 \%$, $7.6 \%$ and $0.75 \%$, respectively. Only 16 of 91 (17.6\%) children were using spectacles and the rest were unaware of the problem. Refractive error was the cause of visual impairment in $76.8 \%$ of participants, amblyopia in $22.0 \%$, trachoma in $2.4 \%$, and corneal opacity and cataract in $0.6 \%$. Anterior segment abnormalities were found in $8.3 \%$, mainly vernal keratoconjunctivitis, while posterior abnormalities were observed in $0.7 \%$. Prevalence of myopia was $9.1 \%$, hypermetropia $2.7 \%$ and astigmatism $3.9 \%$. Prevalence of visual impairment because of Refractive Error was associated with increasing age, but there was no significant association with school grade or sex.

Conclusion: Prevalence of visual impairment among school-aged children in Hargeisa was high, and the leading cause was uncorrected Refractive Error. There are barriers to care and it is critical that they are overcome.

Keywords: refractive error, childhood visual impairment, myopia, hypermetropia, vernal keratoconjunctivitis

Citation: Abdi Ahmed Z; Alrasheed SH; Alghamdi W. Prevalence of refractive error and visual impairment among school-age children of Hargesia, Somaliland, Somalia. East Mediterr Health J. 2020;26(11):1362-1370. https://doi.org/10.26719/emhj.20.077

Received: 18/03/19; accepted: 19/11/19

Copyright $\odot$ World Health Organization (WHO) 2020. Open Access. Some rights reserved. This work is available under the CC BY-NC-SA 3.0 IGO license (https://creativecommons.org/licenses/by-nc-sa/3.o/igo).
\end{abstract}

\section{Introduction}

Globally, it is estimated that there are 36 million people who are blind, 216.6 million have moderate to severe visual impairment (VI) and 188.5 million have mild VI. The leading cause of VI is uncorrected refractive error (RE) $(1,2)$. Furthermore, 90\% of people with VI live in developing countries. Almost 19 million children aged $<15$ years have VI globally. In developing countries, $7-31 \%$ of childhood blindness is avoidable, $10-58 \%$ is treatable, and $3-28 \%$ is preventable (3). RE is an eye condition in which light from a distant object is not focused on the retina; it might be focused in front of or behind the retina. There are 3 types of RE: myopia, hypermetropia and astigmatism. The exact cause of ametropia remains unknown with common risk factors being hereditary, nutritional and environmental (4). Population-based studies on VI and RE in children have been conducted on populations with different racial backgrounds and environments in Africa. These studies have shown that the prevalence of VI among children was $2.15 \%$ in South Africa (5), 5.5\% in Khartoum, Sudan (6), 4.4\% in South Darfur, Sudan (7), and 9.5\% in Ethiopia (8). World Health Organization (WHO) defines VI in children as presenting with visual acuity (VA) less than 6/12 in the better eye. However, uncorrected VA (UVA) is defined as VA less than 6/12 in one or both eyes (7). VI among children in developing countries is a priority of eye health programmes, including Vision 2020: the Right to Sight Initiative (9). Globally, the principal cause of VI is uncorrected REs (43\%) and cataracts (33\%) (1). Special attention should be given to children, because VI restricts their education and general performance, personality development, future quality of life and career opportunities (10). The Refractive Error Study in Children (RESC) protocol was developed by WHO in collaboration with, and under financial support from the National Eye Institute, National Institutes of Health and the United States of America to assess the prevalence of VI and RE worldwide, as well as to assess the effect of childhood VI due to uncorrected RE (11,12).

Somaliland, Somalia has a population of 4.5 million, with estimated urban poverty of $29 \%$, which is similar to $26 \%$ in Ethiopia. Only about half of children aged 6-13 years go to primary school in Somaliland, in stark contrast to $87 \%$ in neighbouring Ethiopia $(13,14)$. No 
studies have assessed VI and RE among school-aged children in Hargeisa, Somaliland. The aims of this study were to assess the common causes of VI, types of RE, and differences in prevalence according to sex, age and school grade.

\section{Methods}

\section{Study design}

This was a cross-sectional, school-based study of VI and RE among children from Hargeisa, Somaliland. According to the Ministry of Education, the overall number of students enrolled in public and private primary schools in Hargeisa during 2017-2018 was 243 485, comprising 127829 boys and 115656 girls. The modified RESC protocol was used to assess the prevalence of VI and RE in these children. Noncycloplegic refraction was used to assess the prevalence of RE, which is defined as follows: (1) myopia $\geq-0.5 \mathrm{D}$ in one or both eyes; (2) hypermetropia $\geq$ $2.0 \mathrm{D}$; and (3) astigmatism $\geq 0.75 \mathrm{D}$ cylindrical refraction (11).

\section{Inclusion and exclusion criteria}

Children aged 6-15 years who attended school on the days of examination and their parents agreed to participate in the study. Children unable to provide parental consent were excluded.

\section{Study sample}

The study sample was selected through stratified multistage sampling. We assumed a prevalence of RE of $5 \%$ according to the estimated prevalence of childhood RE in Africa (5\%), Sudan (6.8\%) (5) and Kenya $(5.1 \%)(15,16)$. Considering a prevalance of $\mathrm{RE}$ of $5 \%, 95 \%$ confidence interval and maximum acceptable random sampling error of $1.5 \%$, a sample size of 811 , based on the formula below, was estimated. Considering the design effect $=1.5$, a final sample of 1216 was estimated.

$n=\left(z^{2} p q\right) / d^{2}=\left(1.96^{2} \times 0.05 \times 0.95\right) / 0.015^{2}=811=>811 \times 1.5=1216$

Considering a nonresponse rate $=10 \%$, the final sample size was 1351 schoolchildren. The study sample comprised 8 schools ( 4 for boys and 4 for girls) that were randomly selected from 22 districts of Hargesia. One class from each grade (1-8) with a minimum of 21 children was randomly chosen.

\section{Ethical considerations}

Ethical permission for the study was obtained from AlNeelain University, Khartoum, Sudan because of unavailability of an ethics committee in Somaliland. The study was conducted according to the Declaration of Helsinki guidelines. Informed consent was obtained from all participants. All forms and data sheets were shredded as soon as the details were entered into the database system for analysis.

\section{Clinical investigation}

The clinical examinations were performed using the modified RESC protocol. Demographic information was collected from participants, and VA at distance was measured using the Snellen Tumbling E-chart with E's of standard size at a 6-m distance. Participants with VA $\leq$ 6/12 were assessed by pinhole test, and if their vision improved, they underwent retinoscopy without cycloplegia and subjective refraction. All children were examined by a penlight and low-power hand magnifier to assess any anterior-segment abnormalities in the eyelids, conjunctiva, cornea, pupils and pupillary reflex reaction. A cover test was conducted for heterophoria or heterotropia and the angle of deviation was measured using the corneal light reflex (Hirschberg test) and the Prism Cover Test at distance and near fixation, respectively. The ocular motility test was performed to assess eye muscle function. Subjective refraction was determined using a standard refraction trial set to achieve best correct vision for children whose vision improved with the pinhole test. Children with VA $\leq 6 / 12$ whose vision did not improve by pinhole test had outer eye and fundus examination by direct ophthalmoscopy, and any abnormal findings were recorded as causes of VI.

\section{Data analysis}

Data for each participant were analysed descriptively using standard deviations and percentages with SPSS version 22. The relationship between measures was determined using correlation, cross-tabulations and $\chi^{2}$ analysis. For all statistical determinations, significance levels were established at $P=0.05$.

\section{Results}

\section{Study population}

A total of 1351 children were selected to participate in the study and $1204(89 \%)$ were actually entered into the study.

\section{Demographic characteristics of participants}

The 1204 participants were aged 6-15 years, with a mean of 11.18 [standard deviation (SD); 2.45] years (Table 1). There were 658 (54.7\%) boys and 546 girls (45.3\%). The mean (SD) age of the boys and girls was 11.15 (2.47) and 11.21 (2.44) years, respectively. Most participants were aged $11(14.2 \%)$ and $12(13.7 \%)$ years, respectively. The ages with the fewest participants were $6(3.2 \%)$ and 7 (5.1\%) years, respectively. There was no significant difference in mean age between the boys and girls (ANOVA: $F=$ $0.167, P=0.683$ ), although there was a significant difference in mean ages of the children according to school grades (ANOVA: $F=341.733, P=0.01$ ).

\section{Distribution of ocular signs and symptoms}

A total of $943(78.8 \%)$ participants did not complain of any ocular symptoms; 153 (12.7\%) complained of blurred vision; $87(7.2 \%)$ had itching and redness; and $15(1.2 \%)$ had pain and photophobia. 


\begin{tabular}{|c|c|c|c|c|c|c|}
\hline \multirow[t]{3}{*}{ Age (years) } & \multicolumn{4}{|c|}{ Sex } & \multicolumn{2}{|c|}{ Total } \\
\hline & \multicolumn{2}{|c|}{ Male } & \multicolumn{2}{|c|}{ Female } & \multirow[b]{2}{*}{$n$} & \multirow[b]{2}{*}{$\%$} \\
\hline & $\mathbf{n}$ & $\%$ & $\mathbf{n}$ & $\%$ & & \\
\hline 6 & 20 & 3.0 & 18 & 3.3 & 38 & 3.2 \\
\hline 7 & 35 & 5.3 & 27 & 4.9 & 62 & 5.1 \\
\hline 8 & 58 & 8.8 & 40 & 7.3 & 98 & 8.1 \\
\hline 9 & 58 & 8.8 & 57 & 10.4 & 115 & 9.6 \\
\hline 10 & 95 & 14.4 & 62 & 11.4 & 157 & 13.0 \\
\hline 11 & 92 & 14.0 & 79 & 14.5 & 171 & 14.2 \\
\hline 12 & 80 & 12.2 & 85 & 15.6 & 165 & 13.7 \\
\hline 13 & 83 & 12.6 & 66 & 12.1 & 149 & 12.4 \\
\hline 14 & 71 & 10.8 & 58 & 10.6 & 129 & 10.7 \\
\hline 15 & 66 & 10.1 & 54 & 9.9 & 120 & 10.0 \\
\hline Total & & & & & & \\
\hline
\end{tabular}

\section{VA}

A total of 1044 children presented with normal vision (6/6) in the right eye; 1034 had normal vision in the left eye; and 1071 had normal vision in the better eye (Table 2). Thirty-six, 38 and 42 children had uncorrected vision (6/9) in the right, left and better eye, respectively. An uncorrected VI was found in 164 children (13.6\%, 95\% CI, $11.7-15.5 \%$ ), while 91 (7.6\%, 95\% CI, $6.1-9.1 \%$ ) children had VI. With best-corrected VA, this decreased to 9 (0.75\%, 95\% CI, 0.3-1.2\%) children.

\section{Prevalence of VI}

The prevalence of presenting VI was 91 (7.6\%, 95\% CI, $6.1-9.1 \%)$ and only $16(17.6 \%)$ of these children were wearing spectacles. There were no significant association between prevalence of VI and age $(P=0.209)$, sex $(P=0.060)$ and school grade $(P=0.393)$. Girls had a higher prevalence of VI (4.6\%, 95\% CI, 3.4-5.8) than boys had $(2.6 \%, 95 \%$ CI, $1.7-3.5 \%)$. Younger children age 6-7 years had lower prev- alence of VI $(2 \%, 95 \%$ CI, $1.2-2.8 \%)$ than those aged $10-11$ years $(3.4 \%, 95 \% \mathrm{CI}, 2.4-4.4 \%)$, and the highest prevalence was in children aged $14-15$ years $(4.4 \%, 95 \% \mathrm{CI}, 3.2-5.7 \%)$.

\section{Binocular anomalies}

Tropia was found in $9(0.7 \%)$ children: 4 with esotropia and 5 with exotropia.

\section{Anterior-segment examination}

A total of 1104 children (91.7\%, 95\% CI, 90.1-93.3\%) had no abnormalities detected in the right eye and 1103 (91.6\%, 95\% CI, 90.0-93.2) had no abnormalities in the left eye. Ninety-seven children $(8.1 \%, 95 \%$ CI $6.6-9.6 \%)$ had vernal keratoconjunctivitis in both eyes. Three children $(0.25 \%$, 95\% CI, 0.03-0.5\%) had trachoma in the left eye and 2 (0.2\%, 95\% CI, $0.1-0.5 \%)$ had trachoma in the right eye. One child had cataract in the right eye $(0.1 \%, 95 \% \mathrm{CI},-0.1$ to $0.3 \%$ ) and one $(0.1 \%, 95 \% \mathrm{CI}, 0-0.3 \%)$ had corneal opacity in the left eye.

\begin{tabular}{|c|c|c|c|c|c|c|c|c|}
\hline \multirow[t]{2}{*}{ UVA } & \multicolumn{2}{|c|}{ Right eye } & \multicolumn{2}{|c|}{ Left eye } & \multicolumn{2}{|c|}{ Better eye } & \multicolumn{2}{|c|}{ Best-corrected VA } \\
\hline & $n$ & $\%(95 \% \mathrm{CI})$ & $n$ & $\%(95 \% \mathrm{CI})$ & $n$ & $\%(95 \% \mathrm{CI})$ & $n$ & $\%(95 \% \mathrm{CI})$ \\
\hline $6 / 6$ & 1044 & $86.7(84.8-88.6)$ & 1034 & $85.9(83.9-87.9)$ & 1071 & $89.0(87.2-90.8)$ & 1182 & $98.1(97.5-99.0)$ \\
\hline $6 / 9$ & 36 & $3.0(2.0-4.0)$ & 38 & $3.2(2.2-4.2)$ & 42 & $3.5(2.5-4.5)$ & 13 & $1.08(0.5-1.7)$ \\
\hline $6 / 12$ & 21 & $1.7(1.0-2.4)$ & 28 & $2.3(1.5-3.2 \%)$ & 24 & $2.0(1.2-2.8)$ & 3 & $0.25(0.03-0.53)$ \\
\hline $6 / 18$ & 32 & $2.7(1.8-3.6)$ & 32 & $2.7(1.8-3.6)$ & 31 & $2.6(1.7-3.5)$ & 2 & $0.17(0.0-0.4)$ \\
\hline $6 / 24$ & 29 & $2.4(1.5-3.3)$ & 32 & $2.7(1.8-3.6 \%)$ & 19 & $1.6(0.9-2.3)$ & 2 & $0.17(0.0-0.4)$ \\
\hline $6 / 36$ & 23 & $1.9(1.13-2.67)$ & 19 & $1.6(0.9-2.3)$ & 9 & $0.7(0.2-1.2)$ & 2 & $0.17(0.0-0.4)$ \\
\hline $6 / 60$ & 12 & $1.0(0.4-1.6)$ & 13 & $1.1(0.5-1.7)$ & 4 & $0.3(0.01-0.61)$ & - & - \\
\hline $\mathrm{CF}$ & 6 & $0.5(0.1-0.9)$ & 7 & $0.6(0.16-1.04)$ & 4 & $0.3(0.01-0.61)$ & - & - \\
\hline HM & 1 & $0.1(0.0-0.3)$ & 1 & $0.1(0.0-0.3)$ & - & - & - & - \\
\hline \multirow[t]{2}{*}{ Total } & 1204 & $100.0 \%$ & 1204 & $100 \%$ & 1204 & $100.0 \%$ & 1204 & $\% 100.0$ \\
\hline & & $\mathrm{VA} \geq 6 / 12$ & & & 91 & $7.6(6.1-9.1)$ & 9 & $0.75(0.3-1.2)$ \\
\hline
\end{tabular}

$C F=$ count fingers; $C I=$ confidence interval; $H M=$ hand movement $\mathrm{UVA}=$ uncorrected visual acuity; $\mathrm{VA}=$ visual acuity. 


\section{Prevalence of $R E$}

A total of 189 children $(15.7 \%, 95 \%$ CI, $13.7-17.8 \%$ ) had REs, and 1015 (84.3\%, 95\% CI, 82.3-86.4\%) were emmetropic (Table 3). Myopia had the highest prevalence $(n=110,9.1 \%)$, followed by astigmatism $(n=47,3.9 \%)$ and hypermetropia $(n=32,2.7 \%$ ). The prevalence of RE was significantly associated with age $(P=0.011)$ but not sex $(P=0.073)$ or school grade $(P=0.168)$. Prevalence of REs was higher among girls $(n=100,18.3 \%)$ than boys $(n=89,13.5)$. Prevalence of REs significantly increased with age. Children aged 15 years had the highest prevalence $(n=21$; $17.5 \%)$, compared to those aged 8 years $(n=14,14.3 \%)$, 7 years $(n=10,16.1 \%)$ and 6 years $(n=5,13.2 \%)$. Children in school grade 4 had the highest prevalence of REs ( $\mathrm{n}=$ $33,21.9 \%$ ), and those in grade 2 had the lowest prevalence $(n=16,10.7 \%$ ). The prevalence of myopia was increase with age; it was more common in children aged 15 years $(10.8 \%)$ than in those aged $6(5.3 \%), 7(8.1 \%)$ and $8(7.1 \%)$ years. In contrast, prevalence of hypermetropia was highest in children aged 6 years $(5.3 \%)$, and lowest in those aged 15 years $(0.8 \%)$. According to the gender the prevalence of myopia, hypermetropia and astigmatism was higher in girls at 10.3, 2.7 and 5.3\%, respectively, than in boys at 8.2, 2.6 and 2.7\%, respectively.

\section{Posterior-segment examination}

Posterior-segment examination revealed that 1196 children (99.3\%, 95\% CI, 98.8-99.8\%) had no abnormalities. Ocular media and fundus abnormalities were seen in 8 $(0.7 \%)$ children. Retinal disorders were found in $6(0.5 \%)$ children and media opacity in 2 ( $0.2 \%)$.

\section{Principal causes of VI}

The causes of UVA of 6/12 or worse at least in 1 eye are presented in Table 4. RE was the main cause of VI in 126 (76.8\%) affected children, followed by amblyopia $(n=36$, $22.0 \%)$ and corneal opacity and cataract $(n=1,0.6 \%)$.

\section{Schoolchildren who received eye drops or were referred}

One hundred and forty-two children $(11.8 \%$, 95\% CI, 10.013.6\%) had uncorrected REs and were referred to Manhal Specialist Hospital, Hargeisa. Two children were referred for further examination and treatment of media opacity. Eighty-seven children $(7.2 \%, 95 \% \mathrm{CI}, 5.7-8.7 \%)$ were prescribed eye drops, and $15(1.2 \%, 95 \% \mathrm{CI}, 0.6-1.8 \%)$ received only advice for their complaints.

\section{Discussion}

Childhood blindness and VI are priority conditions targeted in Vision 2020: the Right to Sight Initiative of WHO

\begin{tabular}{|c|c|c|c|c|c|c|c|c|c|c|c|c|c|}
\hline \multirow[t]{2}{*}{ Category } & & \multicolumn{2}{|c|}{$\begin{array}{c}\text { Emmetropia } \\
(95 \% \mathrm{CI}, \mathbf{8 2 . 3}-\mathbf{8 6 . 4})\end{array}$} & \multicolumn{2}{|c|}{$\begin{array}{c}\text { Myopia } \\
(95 \% \text { CI, } 7.5-10.7)\end{array}$} & \multicolumn{2}{|c|}{$\begin{array}{l}\text { Hypermetropia } \\
(95 \% \text { CI, 1.8-3.6) }\end{array}$} & \multicolumn{2}{|c|}{$\begin{array}{c}\text { Astigmatism } \\
(95 \% \mathrm{CI}, 2.8-5.0)\end{array}$} & \multicolumn{2}{|c|}{$\begin{array}{l}\text { no funds reflex } \\
(95 \% \mathrm{CI}, 1.4-1.6)\end{array}$} & \multicolumn{2}{|c|}{ Total } \\
\hline & & $n$ & $\%$ & $n$ & $\%$ & $n$ & $\%$ & $n$ & $\%$ & $n$ & $\%$ & $n$ & $\%$ \\
\hline \multirow{10}{*}{$\begin{array}{l}\text { Age } \\
\qquad(P=0.011)\end{array}$} & 6 & 33 & 86.8 & 2 & $5 \cdot 3$ & 2 & $5 \cdot 3$ & 1 & 2.6 & 0 & 0 & 38 & 3.2 \\
\hline & 7 & 52 & 83.9 & 5 & 8.1 & 3 & 4.8 & 2 & 3.2 & 0 & 0 & 62 & 5.1 \\
\hline & 8 & 84 & 85.7 & 7 & 7.1 & 5 & 5.1 & 2 & 2.0 & 0 & 0 & 98 & 8.1 \\
\hline & 9 & 100 & 87.0 & 9 & 7.8 & 5 & 4.3 & 1 & 0.9 & 0 & 0 & 115 & 9.6 \\
\hline & 10 & 132 & 84.1 & 14 & 8.9 & 4 & 2.5 & 7 & 4.5 & 0 & 0 & 157 & 13.0 \\
\hline & 11 & 145 & 84.8 & 17 & 9.9 & 2 & 1.2 & 7 & 4.1 & 0 & 0 & 171 & 14.2 \\
\hline & 12 & 136 & 82.4 & 17 & 10.3 & 6 & 3.6 & 6 & 3,6 & 1 & 0.6 & 165 & 13.7 \\
\hline & 13 & 129 & 86.6 & 13 & 8.7 & 2 & 1.3 & 5 & 3.4 & 0 & 0 & 149 & 12.4 \\
\hline & 14 & 105 & 81.4 & 13 & 10.1 & 2 & 1.6 & 9 & 7.0 & 0 & 0 & 129 & 10.7 \\
\hline & 15 & 99 & 82.5 & 13 & 10.8 & 1 & 0.8 & 7 & 5.8 & 0 & 0 & 120 & 10.0 \\
\hline \multirow{2}{*}{$\begin{array}{l}\text { Sex } \\
\qquad(P=0.073)\end{array}$} & M & 569 & 90.6 & 54 & 8.2 & 17 & 2.6 & 18 & 2.7 & 0 & 0 & 658 & 54.7 \\
\hline & $\mathrm{F}$ & 445 & 81.5 & 56 & 10.3 & 15 & 2.7 & 29 & $5 \cdot 3$ & 1 & 0.2 & 546 & $45 \cdot 3$ \\
\hline \multirow{8}{*}{$\begin{array}{l}\text { Class level } \\
\qquad(P=0.168)\end{array}$} & 1 & 129 & 87.2 & 6 & 4.1 & 7 & 4.7 & 6 & 4.1 & 0 & 0 & 148 & 12.3 \\
\hline & 2 & 134 & 89.3 & 10 & 6.7 & 3 & 2.0 & 3 & 2.0 & 0 & 0 & 150 & 12.5 \\
\hline & 3 & 122 & 81.3 & 17 & 11.3 & 7 & 4.7 & 4 & 2.7 & 0 & 0 & 150 & 12.5 \\
\hline & 4 & 118 & 78.1 & 22 & 14.6 & 3 & 2.0 & 7 & 4.6 & 1 & 0.7 & 151 & 12.5 \\
\hline & 5 & 130 & 86.1 & 12 & 8.0 & 4 & 2.6 & 5 & 3.3 & 0 & 0 & 151 & 12.5 \\
\hline & 6 & 130 & 85.5 & 11 & 7.2 & 3 & 2.0 & 8 & $5 \cdot 3$ & 0 & 0 & 152 & 12.6 \\
\hline & 7 & 122 & 80.8 & 18 & 11.9 & 3 & 2.0 & 8 & $5 \cdot 3$ & 0 & 0 & 151 & 12.5 \\
\hline & 8 & 129 & 85.4 & 14 & 9.3 & 2 & 1.3 & 6 & 4.0 & 0 & 0 & 151 & 12.5 \\
\hline Total & & 1015 & 84.3 & 110 & 9.1 & 32 & 2.7 & 47 & 3.9 & 1 & 0.1 & 1204 & $100 \%$ \\
\hline
\end{tabular}




\begin{tabular}{|c|c|c|c|}
\hline \multirow[t]{2}{*}{ Causes } & \multicolumn{2}{|c|}{$\begin{array}{l}\text { Children with VA } 6 / 12 \text { or worse in one } \\
\text { or both eyes }\end{array}$} & \multirow[t]{2}{*}{$\begin{array}{l}\text { Prevalence in the population in one or both eyes, } \\
\qquad \%(95 \% \mathrm{CI})\end{array}$} \\
\hline & $n$ & $\%$ & \\
\hline Refractive error & 126 & 76.8 & $10.5(8.8-12.2)$ \\
\hline Amblyopia & 36 & 22.0 & $3.0(2.04-4.0)$ \\
\hline Corneal opacity & 1 & 0.6 & $0.08(-0.08$ to 0.24$)$ \\
\hline Cataract & 1 & 0.6 & $0.08(0.08-0.24)$ \\
\hline Any cause & 164 & 100.0 & $13.6(11.7-15.5)$ \\
\hline
\end{tabular}

(17). Knowledge of the prevalence of RE and VI among school age children can help the relevant authorities to plan and provide eye care services in the particular geographical area. The present study attempted to provide this information, as well as being the first study in Somaliland to assess the prevalence of the VI and RE among school-aged children.

Noncycloplegic refraction was used to assess REs in this study, similar to studies of school-aged children in Nigeria (18) and South Africa (19). Noncycloplegic refraction was chosen so as not to interfere with the academic activity of the children.

The prevalence of VI in the present study was $7.6 \%$, which is lower than $10.1 \%$ in Malaysia (20) and $10.3 \%$ in China (21), but higher compared with $1.2 \%$ in South Africa (5) $1.2 \%, 2.67 \%$ in South America (22) and 3.5\% in the Islamic Republic of Iran (23). These results indicate that VI among school-aged children requires urgent intervention by the community and nongovernmental organizations. The results also reflect lack of childhood eye care services in this region as well as lack of community awareness about the consequences of childhood VI.

In the present study, the prevalence of VI was higher among girls than boys (4.6\% vs $2.6 \%$ ), which agrees with a study in Ethiopia (3.2\% for girls and $2.6 \%$ for boys) (24). This might have been due to socioeconomic factors that contributed to better access to health services for boys. However, the difference was not significant.

The prevalence of RE in either eye was $15.7 \%$, which is lower than that in Ghana (25.6\%) (25), India (25.1\%) (26), Egypt (22.1\%) (27) and Qatar (19.7\%) (28), but higher than in Uganda (11.6\%) (29), Ghana (13.3\%) (30) and Saudi Arabia (13.7\%) (31). The prevalence of RE in our study was similar to that in Viet Nam (16.3\%) (32) and Saudi Arabia (16.3\%) (33). This variation may be related to the type of sampling method used, size of population screened, and variation in geographic location. We found no significant association between prevalence of RE and school grade or sex. However, we did show that the prevalence of VI caused by uncorrected RE increased significantly with age. Nevertheless, we found that prevalence of RE was higher among girls than boys ( $81.3 \%$ vs $13.5 \%$ ), which, as mentioned above, might have been due to better access to health care for boys in this culture. This is consistent with a similar study in Saudi Arabia (34).
The prevalence of myopia was $9.1 \%$, which is higher than $6.0 \%$ in Ethiopia (24) but lower than $14.1 \%$ in Ghana (30). In our study, older school children had a higher prevalence of myopia, which was similar to a study in Viet Nam (32). Alrasheed et al. (7) attributed this ageassociated increase in myopia with decreased outdoor activity of many children and this has been reported as an issue in other studies $(5,25,32)$.

The prevalence of hypermetropia in this study was $2.7 \%$, which is significantly lower than that reported in studies in Ethiopia 26.4\% (24) and Saudi Arabia 6.9\% (35). However, it is higher than in South Africa (1.8\%) (10) and China (1.6\%) (36) but similar to Tunisia (2.61\%) (37). The lower prevalence of hypermetropia in our study might have been due to use of noncycloplegic refraction, which could have missed a significant number of cases of hypermetropia. The prevalence of hypermetropia decreased with age and was higher in children aged 6 and 7 years compared with 14 and 15 years. This result agreed with Chebil et al. (37), who reported that this variation could be related to a decrease in the dioptric power of the lens (it goes form $23 \mathrm{D}$ at age 3 years to $20 \mathrm{D}$ at 14 years), or with an increase in the optical density of the crystalline cortex.

The prevalence of astigmatism in the current study was $3.9 \%$. This is lower than that found in the Islamic Republic of Iran (6.6\%) (38) and South Africa (14.6\%) (5) but similar to that in Poland (4\%) (39).

The prevalence of manifest strabismus was $0.7 \%$, which is similar to that among children in the United Republic of Tanzania (0.5\%) (40) but lower than in Iranian school children (1.2\%) (41).

In this study, uncorrected RE was the most common cause of VI among children, and was responsible for $76.8 \%$ of cases. This is similar to other studies that used RESC protocol, such as in Ethiopia (77.3\%) (24) and India (77\%) (26) but lower than in Malaysia (87.0\%) (20) and in the Islamic Republic of Iran (87.3\%) (23). Alrasheed et al. (7) suggested that this could have been because of genetic differences as well as different lifestyles in terms of outdoor activities. The second most frequent cause of VI among children was amblyopia at $22.0 \%$, which is higher than in Sudan (5.6\%) (6) and South Africa (9.6\%) (4). This may be due to the high rate of poverty and illiteracy in Somaliland and the poor health system in the country. 
In the present study, out of 91 children with VI, only $16(17.6 \%)$ were already using spectacles, while the rest were not aware of the problem. This may have been due to lack of child and parental awareness of the vision problem, attitudes regarding the need for spectacles, cost of spectacles, cosmetic appearance, peer pressure and concerns that wearing glasses may cause progression of $\operatorname{RE}(42,43)$.

This study had several limitations. First, a large number of schools were not registered with the Ministry of Education in Hargeisa, so the study sample did not include all schools. Second, almost half of school-age children were not attending school due to poverty, thus the study only included children who attended school. Third, places of study and examination differed among schools in terms of lighting, ventilation and comfort. Fourth, distribution of children's ages at school levels was not uniform, so older children were not only in the eighth and seventh grades, and children aged 6 and 7 years were less prevalent in this study, because many children in Somaliland start school later than the recommended 6 years. Fifth, Log Mar charts were not available, so we used Snellen Tumbling E-charts, and slit lamps and fundus biomicroscopy were not easy to transport between locations, so they were replaced by torch and magnifier, and ophthalmoscopy. Finally, RE was assessed by noncycloplegic refraction, which could have missed a significant number of cases of hypermetropia.

\section{Conclusions}

The prevalence of VI among school-aged children in Hargeisa, Somaliland was high and the commonest causes were uncorrected REs. There are barriers to care and it is critical that they are overcome.

\section{Acknowledgement}

We are grateful to all schools included in this study and their staff for help with data collection. We also thank all the students who participated in this study and their parents, as well as the students of the Faculty of Optometry and Visual Science, University Of Hargeisa. We are grateful to Manhal Specialist Hospital, which provided us with the required instrumentation, and free treatment for any student who was referred to the hospital.

Funding: None.

Competing interests: None declared.

\section{Prévalence du vice de réfraction et de la déficience visuelle chez les enfants d'âge sco- laire de Hargesia, au Somaliland (Somalie) \\ Résumé}

Contexte : Les troubles visuels chez l'enfant constituent un problème de santé publique mondial, en particulier dans les pays en développement. Ses causes les plus courantes sont évitables par un diagnostic précoce et la mise en place rapide d'un traitement.

Objectifs : La présente étude avait pour objectif d'évaluer la prévalence du vice de réfraction et de la déficience visuelle chez les enfants d'âge scolaire à Hargeisa, au Somaliland (Somalie).

Méthodes : Il s'agissait d'une étude transversale menée auprès de 1204 élèves (âgés de 6 à 15 ans) de huit écoles primaires sélectionnées de manière aléatoire à Hargeisa, entre novembre 2017 et janvier 2018. Nous avons utilisé l'étude modifiée sur le vice de réfraction chez les enfants afin de déterminer la prévalence de cette affection et de la déficience visuelle, comprenant les examens suivants : acuité visuelle à distance, évaluée par l'échelle de Snellen avec des E ou C directionnels ; la réfraction, évaluée par examen de la vision binoculaire par rétinoscopie; et examen des segments antérieurs et postérieurs.

Résultats : La prévalence de la déficience visuelle non corrigée, détectée et la mieux corrigée de 6/12 ou un score inférieur était respectivement de $13,6 \%$, de 7,6\% et de 0,75\%. Seuls 16 enfants sur $91(17,6 \%)$ portaient des lunettes tandis que les autres navaient pas conscience du problème. Le vice de réfraction était la cause de la déficience visuelle chez 76,8\% des participants, l'amblyopie dans $22,0 \%$ des cas, le trachome chez 2,4\% des enfants, et l'opacité cornéenne et la cataracte chez $0,6 \%$ d'entre eux. Des anomalies du segment antérieur ont été observées chez $8,3 \%$ des participants à létude, principalement des kératoconjonctivites vernales, tandis que des anomalies du segment postérieur ont été observées dans $0,7 \%$ des cas. La prévalence de la myopie était de 9,1\%, celle de l'hypermétropie de 2,7 \% et celle de l'astigmatisme de 3,9\%. La prévalence de la déficience visuelle due à un vice de réfraction était associée à un âge supérieur, sans toutefois que l'on puisse noter de corrélation significative avec le niveau scolaire ou le sexe.

Conclusion : La prévalence de la déficience visuelle chez les enfants d'âge scolaire de Hargesia était élevée, principalement en raison d'un vice de réfraction non corrigé. Il existe des obstacles aux soins et il est essentiel de les surmonter. 
معدل انتشار الخطأ الانكساري وضعف البصر بين الأطفال في سن الدراسة في هرجيسا، صوماليلاند (الصومال)

$$
\text { زهرة عبدي أحم، سيف الرشيد، وليد الغامدي }
$$

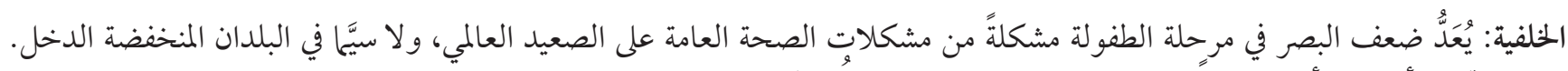

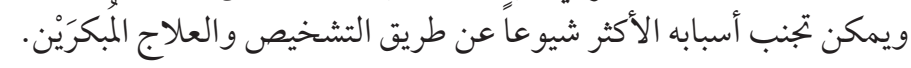

الأهداف: هدفت هذه الدراسة إلى تقييم معدل انتشار الخطأ الانكساري وضعف البصن البصر بين الأطفال في سن الدراسة في هرجيسا، صوماليلاند

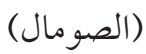

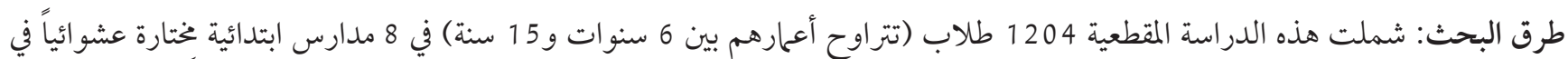

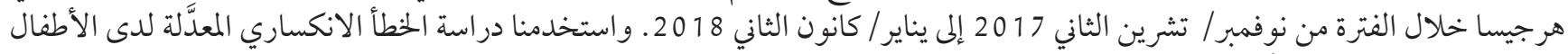

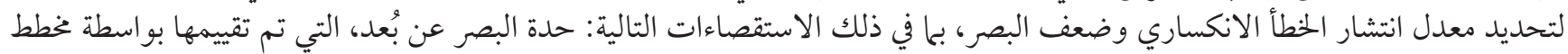
Snellen Tumbling E-chart

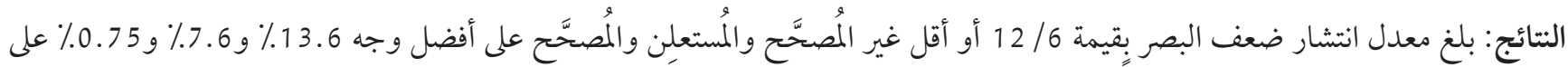

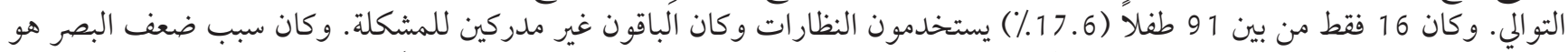

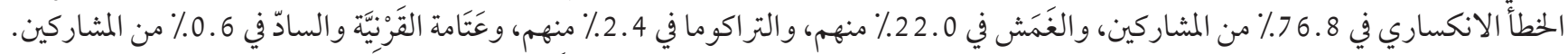

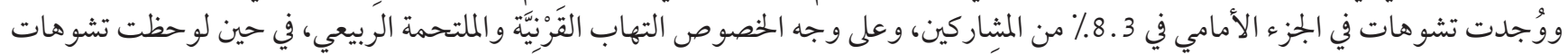

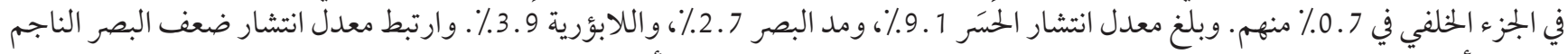

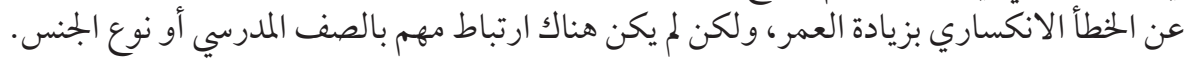

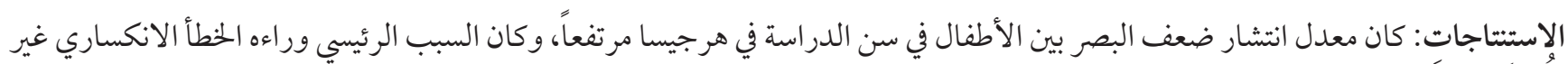

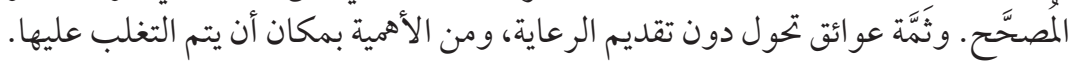

\section{References}

1. Bourne RRA, Flaxman SR, Braithwaite T, Cicinelli MV, Das A, Jonas JB et al. Magnitude, temporal trends, and projections of the global prevalence of blindness and distance and near vision impairment: a systematic review and meta-analysis. Lancet Glob Health. 2017;5(9):e888-97. http://dx.doi.org/10.1016/S2214-109X(17)30293-o PMID:28779882

2. Flaxman SR, Bourne RRA, Resnikoff S, Ackland P, Braithwaite T, Cicinelli MV et al. Global causes of blindness and distance vision impairment 1990-2020: a systematic review and meta-analysis. Lancet Glob Health. 2017;5(12):e1221-34. http://dx.doi. org/10.1016/S2214-109X(17)30393-5 PMID:29032195

3. Kong L, Fry M, Al-Samarraie M, Gilbert C, Steinkuller PG. An update on progress and the changing epidemiology of causes of childhood blindness worldwide. J AAPOS. 2012 Dec;16(6):501-7. http://dx.doi.org/10.1016/j.jaapos.2012.09.004 PMID:23237744

4. Benjamin WJ. Borish's clinical refraction E-book. Elsevier Health Sciences; 2006

5. Naidoo KS, Raghunandan A, Mashige KP, Govender P, Holden BA, Pokharel GP, Ellwein LB. Refractive error and visual impairment in African children in South Africa. Invest Ophthalmol Vis Sci. 2003 Sep;44(9):3764-70. http://dx.doi.org/10.1167/iovs.030283. PMID:12939289

6. Zeidan Z, Hashim K, Muhit MA, Gilbert C. Prevalence and causes of childhood blindness in camps for displaced persons in Khartoum: results of a household survey. East Mediterr Health J. May-Jun 2007;13(3):580-5. PMID:17687831

7. Alrasheed SH, Naidoo KS, Clarke-Farr PC. Prevalence of visual impairment and refractive error in school-aged children in South Darfur State of Sudan. Afr Vis Eye Health. 2016 Oct 27;75(1):1-9. https://doi.org/10.4102/aveh.v75i1.355

8. Mehari ZA, Yimer AW. Prevalence of refractive errors among schoolchildren in rural central Ethiopia. Clin Exp Optom. 2013 Jan;96(1):65-9. http://dx.doi.org/10.1111/j.1444-0938.2012.00762.x PMID:22784031

9. Courtright P, Hutchinson AK, Lewallen S. Visual impairment in children in middle-and lower-income countries. Arch Dis Child. 2011 Dec 1;96(12):1129-34. http://dx.doi.org/10.1136/archdischild-2011-300093 PMID:21868404

10. Holden BA. The role of optometry in Vision 2020. Community Eye Health. 2002;15(43):33-6. PMID:17491876

11. Logan N. The development of refractive error. In: Optometry: science, techniques and clinical management. 2nd ed. Oxford: Elsevier Health Sciences; 2009 Jun 22:159-71.

12. Assessment of the prevalence of visual impairment attributable to refractive error or other causes in school children. Protocol and manual of procedures. Geneva: World Health Organization; 2007 (https://www.who.int/blindness/causes/RESCProtocol. pdf?ua=1, accessed 20 May 2020). 
13. Somalia: Somaliland, including government structure, security, and presence of internally displaced persons (IDPs) from Somalia (2016-March 2018) [website]. Geneva: United Nations High Commissioner for Refugees (https://www.refworld.org/ docid/5ad453514.html, accessed 20 May 2020).

14. New world Bank GDP and poverty estimates for Somaliland [website]. Washington DC: World bank; 2014 (https://www.worldP bank.org/en/news/press-release/2014/01/29/new-world-bank-gdp-and-poverty-estimates-for-somaliland, accessed 20 May 2020).

15. Muma MK, Kimani K, Kariuk, Wanyike MM. Prevalence and significant refractive errors in primary school children of a rural district of Kenya. East Afr J Ophthalmol. 2007;13(2):48-51.

16. Minassian D. Sample size calculation for eye surveys: a simple method. Community Eye Health. 1997;10(23):42-44. https://www. cehjournal.org/article/sample-size-calculation-for-eye-surveys-a-simple-method/

17. The World Health Report 1998: life in the 21st century a vision for all. Geneva: World Health Organization; 1998 (https://www. who.int/whr/1998/en/, accessed 20 May 2020).

18. Adegbehingbe BO, Oladehinde MK, Majemgbasan TO, Onakpoya HO, Osagiede EO. Screening of adolescents for eye diseases in Nigerian high schools. Ghana Med J. 2005 Dec;39(4):138-42. PMCID:PMC1790830

19. Mabaso RG, Oduntan AO, Mpolokeng MB. Refractive status of primary school children in Mopani district, Limpopo Province, South Africa. Afr Vis Eye Health. 2006 Dec 19;65(4):125-33. https://doi.org/10.4102/aveh.v65i4.267

20. Goh PP, Abqariyah Y, Pokharel GP, Ellwein LB. Refractive error and visual impairment in school-age children in Gombak District, Malaysia. Ophthalmology. 2005 Apr 1;112(4):678-85. http://dx.doi.org/10.1016/j.ophtha.2004.10.048 PMID:15808262

21. He M, Huang W, Zheng Y, Huang L, Ellwein LB. Refractive error and visual impairment in school children in rural southern China. Ophthalmology. 2007 Feb ;114(2):374-82. http://dx.doi.org/10.1016/j.ophtha.2006.08.020 PMID:17123622

22. Furtado JM, Lansingh VC, Carter MJ, Milanese MF, Peña BN, Ghersi HA, et al. Causes of blindness and visual impairment in Latin America. Surv Ophthalmol. 2012 Mar-Apr;57(2):149-77. http://dx.doi.org/10.1016/j.survophthal.2011.07.002 PMID:22137039

23. Fotouhi A, Hashemi H, Khabazkhoob M, Mohammad K. The prevalence of refractive errors among schoolchildren in Dezful, Iran. Br J Ophthalmol. 2007 Mar;91(3):287-92. http://dx.doi.org/10.1136/bjo.2006.099937 PMID:17035280

24. Yared AW, Belaynew WT, Destaye S, Ayanaw T, Zelalem E. Prevalence of refractive errors among school children in Gondar Town, Northwest Ethiopia. Middle East Afr J Ophthalmol. 2012 Oct;19(4):372-6. http://dx.doi.org/10.4103/0974-9233.102742 PMID:23248538

25. Ovenseri-Ogbomo GO, Omuemu VO. Prevalence of refractive error among school children in the Cape Coast Municipality, Ghana. Clin Optom. 2010 Jul 3;2:59-66.

26. Padhye AS, Khandekar R, Dharmadhikari S, Dole K, Gogate P, Deshpande M. Prevalence of uncorrected refractive error and other eye problems among urban and rural school children. Middle East African journal of ophthalmology. 2009 Apr;16(2):69-74. http://dx.doi.org/10.4103/0974-9233.53864 PMID:20142964

27. El-Bayoumy BM, Saad A, Choudhury AH. Prevalence of refractive error and low vision among schoolchildren in Cairo. East Mediterr Health J. 2007 May-Jun;13(3):575-80. PMID:17687830

28. Al-Nuaimi AA, Salama RE, Eljack IE. Study of refractive errors among school children Doha. World Fam Med J. 2010;8(7):41-8.

29. Kawuma M, Mayeku R. A survey of the prevalence of refractive errors among children in lower primary schools in Kampala district. Afr Health Sci. 2002 Aug;2(2):69-72. PMID:12789105

30. Ovenseri-Ogbomo GO, Assien R. Refractive error in school children in Agona Swedru, Ghana. Afr Vis Eye Health. 2010 Dec 11;69(2):86-92. https://doi.org/10.4102/aveh.v69i2.129

31. Al Wadaani FA, Amin TT, Ali A, Khan AR. Prevalence and pattern of refractive errors among primary school children in Al Hassa, Saudi Arabia. Glob J Health Sci. 2012 Nov 11;5(1):125-34. http://dx.doi.org/10.5539/gjhs.v5n1p125 PMID:23283044

32. Paudel P, Ramson P, Naduvilath T, Wilson D, Phuong HT, Ho SM, et al. Prevalence of vision impairment and refractive error in school children in Ba Ria -Vung T au province, Vietnam. Clin Exp Ophthalmol. 2014 Apr;42(3):217-26. http://dx.doi.org/10.1111/ ceo.12273 PMID:24299145

33. Aldebasi YH. Prevalence of correctable visual impairment in primary school children in Qassim Province, Saudi Arabia. J Optom. 2014 Jul-Sep;7(3):168-76. http://dx.doi.org/10.1016/j.optom.2014.02.001 PMID:25000873

34. Dandona R, Dandona L, Srinivas M, Sahare P, Narsaiah S, Munoz SR, et al. Refractive error in children in a rural population in India. Invest Ophthalmol Vis Sci. 2002 Mar;43(3):615-22. PMID:11867575

35. Al-Rowaily MA. Prevalence of refractive errors among pre-school children at King Abdulaziz Medical City, Riyadh, Saudi Arabia. Saudi Journal of Ophthalmology. 2010 Apr;24(2):45-8. http://dx.doi.org/10.1016/j.sjopt.2010.01.001 PMID:23960874

36. Li Z, Xu K, Wu S, Lv J, Jin D, Song Z, Wang Z, Liu P. Population $\square$ based survey of refractive error among school $\square$ aged children in rural northern China: the Heilongjiang Eye Study. Clin Exp Ophthalmol. 2014 May-Jun;42(4):379-84. http://dx.doi.org/10.1111/ ceo.12198 PMID:23952961

37. Chebil A, Jedidi L, Chaker N, Kort F, Limaiem R, Mghaieth F, et al. Characteristics of astigmatism in a population of Tunisian school-children. Middle East Afr J Ophthalmol. 2015 Jul-Sep;22(3):331-4. http://dx.doi.org/10.4103/0974-9233.150635 PMID:26180472 
38. Khalaj M, Gasemi M, Zeidi IM. Prevalence of refractive errors in primary school children [7-15 years] of Qazvin City. Eur J Sci Res. 2009;28(2):174-85.

39. Czepita D, Mojsa A, Ustianowska M, Czepita M, Lachowicz E. Prevalence of refractive errors in schoolchildren ranging from 6 to 18 years of age. Ann Acad Med Stetin. 2007;53(1):53-6. PMID:18561610

40. Wedner SH, Ross DA, Balira R, Kaji L, Foster A. Prevalence of eye diseases in primary school children in a rural area of Tanzania. Br J Ophthalmol. 2000 Nov;84(11):1291-7. http://dx.doi.org/10.1136/bjo.84.11.1291 PMID:11049957

41. Jamali P, Fotouhi A, Hashemi H, Younesian M, Jafari A. Refractive errors and amblyopia in children entering school: Shahrood, Iran. Optom Vis Sci. 2009 Apr;86(4):364-9. http://dx.doi.org/10.1097/OPX.obo13e3181993f42 PMID:19289975

42. Alrasheed SH, Naidoo KS, Clarke-Farr PC. Attitudes and perceptions of Sudanese high-school students and their parents towards spectacle wear. Afr Vis Eye Health. 2017 Apr 11;77(1):1-7. https://doi.org/10.4102/aveh.v7711.392

43. Alrasheed SH, Naidoo KS, Clarke-Farr PC, Binnawi KH. Building consensus for the development of child eye care services in South Darfur State in Sudan using the Delphi technique. Afr J Prim Health Care Fam Med. 2018 Oct 24;10(1):1-9. http://dx.doi. org/10.4102/phcfm.v10i1.1767 PMID:30456975 